\title{
Multivariate factorial analysis to design a robust batch leaching test to assess the volcanic ash geochemical hazard
}

Flavia Ruggieri ${ }^{\mathrm{a}}$, Raúl A. Gil ${ }^{\mathrm{b}}$, Jose-Luis Fernandez-Turiel ${ }^{\mathrm{a},{ }^{*}}$, Julio Saavedra ${ }^{\mathrm{c}}$, Domingo

Gimeno $^{\mathrm{d}}$, Agustin Lobo ${ }^{\mathrm{a}}$, Luis D. Martinez ${ }^{\mathrm{b}}$, Alejandro Rodriguez-Gonzalez ${ }^{\mathrm{e}}$

${ }^{a}$ Institute of Earth Sciences Jaume Almera, ICTJA-CSIC, Barcelona, Spain.

${ }^{\mathrm{b}}$ Instituto de Química de San Luis (CCT-San Luis) - Área de Química Analítica, Facultad de Química, Bioquímica y Farmacia, Universidad Nacional de San Luis. San Luis, Argentine.

${ }^{\mathrm{c}}$ IRNASA-CSIC, Salamanca, Spain.

${ }^{d}$ Faculty of Geology, University of Barcelona, Spain.

${ }^{e}$ Departamento de Física (GEOVOL), Universidad de Las Palmas de Gran Canaria, Las Palmas de Gran Canaria, Canary Islands, Spain.

*Corresponding author. E-mail address: jlfernandez@ictja.csic.es 


\begin{abstract}
A method to obtain robust information on short term leaching behaviour of volcanic ashes has been developed independently on the sample age. A Mixed Factorial Design (MFD) was employed as a multivariate strategy for the evaluation of the effects of selected control factors and their interactions (amount of sample (A), contact time (B), and liquid to solid ratio or L/S (C)) on the leaching process of selected metals ( $\mathrm{Na}, \mathrm{K}$, $\mathrm{Mg}, \mathrm{Ca}, \mathrm{Si}, \mathrm{Al}, \mathrm{V}, \mathrm{Mn}, \mathrm{Fe}$, and $\mathrm{Co})$ and anions $\left(\mathrm{Cl}^{-}\right.$and $\left.\mathrm{SO}_{4}{ }^{2-}\right)$. Box plots of the data acquired were used to evaluate the reproducibility achieved at different experimental conditions. Both the amount of sample (A) and leaching time (B) had a significant effect on the element stripping whereas the L/S ratio influenced only few elements. The lowest dispersion values have been observed when $1.0 \mathrm{~g}$ was leached with an L/S ratio equal to 10 , shaking during $4 \mathrm{~h}$. The entire method is completed within few hours, and it is simple, feasible and reliable in laboratory conditions.
\end{abstract}

Keywords: Volcanic ash; Batch leaching; Mixed factorial design 


\section{Introduction}

Explosive volcanic activity can produce ash deposits with a wide spatial distribution that may affect soils and surface waters [1-3]. One of the most important environmental impacts of ash fall is due to the presence of water soluble materials on volcanic ash particle surfaces, feature already documented at the beginning of the XX century [4]. It is well accepted that volcanic ashfall produces a natural contribution of potentially toxic trace elements (PTTEs) on the earth surface after contact with an aqueous environment $[3,5,6]$. From an environmental point of view, the elements leached most rapidly are present as soluble salts on the ash surface whereas prolonged exposure of ash to weathering may cause slow release of other elements from the structure of constituent crystalline phases and glass [7]. Although eruptions are often short-lived, thick ashfall deposits can remain in the local environment for years to decades, and may be resuspended by wind storms, causing long-term environmental effects mainly physically since fine ash may reach the deepest parts of the lungs [8]. However, chemically, resuspended ash is much more inert than pristine ash due to leaching of the former in the environment.

The potential impact on the environment of volcanic ashes disposed on land is most frequently assessed and predicted using bench scale laboratory tests although there are many important environmental conditions present in the field which cannot be reproduced in a laboratory. However, most of the soluble constituents of volcanic ash are detected by one stage batch leaching tests [1, 2, 7-14].

A review of 55 studies reporting ash leachate data for 27 volcanoes concluded that the use of a wide range of methodological variable values (in leachant composition, contact time and liquid to solid or L/S ratio) make the comparison between the different studies difficult [15]. After the exhaustive literature search of leaching protocols of this 
review, Witham et al. [15] proposed a "standard protocol" simply based on the most common used methodologies rather than the optimal conditions. The present study attempts to determine this optimum through logical experiment design, careful measurement, and statistical analysis. A better understanding of experimental conditions allows the identification of the parameters affecting the mobility of PTTEs from ash. Consequently, designing more realistic and appropriate leaching tests will help to model more accurately the environmental impact of volcanic ash.

The aim of this work was to develop a method to obtain robust information on short term leaching behaviour of volcanic ashes. A Mixed Factorial Design (MFD) was built in order to investigate the influence of control factors (and their interactions) over the leaching process of selected metals ( $\mathrm{Na}, \mathrm{K}, \mathrm{Mg}, \mathrm{Ca}, \mathrm{Si}, \mathrm{Al}, \mathrm{V}, \mathrm{Mn}, \mathrm{Fe}$, and $\mathrm{Co}$ ) and anions $\left(\mathrm{Cl}^{-}\right.$and $\left.\mathrm{SO}_{4}{ }^{2-}\right)$ using ANOVA tests. Regression analysis was also used to evaluate the predictability of the single batch leaching process. Finally, box plots of the data acquired were used to evaluate the reproducibility achieved at different experimental conditions.

\section{Experimental}

The rate and amount of element released in a leaching test depend on several factors including chemical and mineral composition of ash, leachant type, and $\mathrm{pH}$ (chemical factors); and, particle size, porosity, contact time, L/S ratio and temperature (physical factors). Among these factors, there is a group intrinsically linked to the properties and composition of ash (primary factors), whereas some others depend on leaching conditions that can be varied to design more suitable procedures (control factors).

For practical purposes, the primary factors and many control factors may be considered fixed in a leaching test. Thus, the number of factors to study experimentally may be 
considerably reduced and the attention can be focused in the most relevant. The fixed factors of the present work were based on the most common protocols used and the recommendations of Witham et al. [15] (e.g., unground and unsieved ash sample, ultrapure water as leachant, room temperature, and $0.45 \mu \mathrm{m}$ membrane filters). On the other hand, the control factors selected to study experimentally were amount of sample, contact time, and L/S, which were varied taking as reference the proposed conditions by Witham et al. [15] (i.e., shake an ash-leach mixture for 90 min in a sealed container; using an ash (g) to water (ml) ratio of 1:25).

\subsection{Sampling and storage}

Two rhyolitic volcanic ash samples described elsewhere [8, 13], have been selected to cover a wide range of ash age. Sample 719 corresponds to an ancient volcanic ash deposit from the southern Puna, NW Argentina, and CHA sample to a pristine volcanic ash erupted in the recent eruption of Chaiten volcano in 2008, Chile. The former sample was collected by a plastic shovel excluding the most superficial $(2 \mathrm{~cm}$ depth) ash to avoid any possible surface contamination [8]. Pristine volcanic ash was collected directly by using plastic trays during the ash fall out. About $1 \mathrm{~kg}$ of samples were placed in polyethylene bags and carried to the laboratory. Samples were dried at $40{ }^{\circ} \mathrm{C}$ in an oven and stored in polyethylene (HDPE) vessels until preparation in the laboratory. Ash drying homogenises the humidity of samples before the leaching experiments and, in the case of pristine ash, preserves the original features of the ash as much as possible.

\subsection{Instrumental}

Concentrations of major elements in volcanic ash leachates were determined by inductively coupled plasma optical emission spectrometry (ICP-OES, Optima 3100, 
Perkin Elmer), and trace elements were determined by using two spectrometers (ICPMS, Elan 6000, PerkinElmer and HR-ICP-MS, Element XR, Thermo Scientific). Ultrapure water was obtained from a Milli-Q system from Millipore (Barnstead, US).

\subsection{Leaching experiments}

The leaching tests were carried out in batch conditions at room temperature, using unground and unsieved volcanic ash, and a non-aggressive leachant as ultrapure water. For each batch leaching test four replicates were run to ensure the trueness of the experimental data, resulting 18 tests by ash sample and a total of 72 leachate samples. The mixture of leachant and ash sample was shaken at $20 \mathrm{rpm}$ at room temperature in polypropylene test tubes $(14 \times 100 \mathrm{~mm})$ or polyethylene (HDPE) reactors (50 and 100 $\mathrm{ml}$ ), depending on the leachate volume. Three different contact times were used in the experiments (1.5, 4 and 16 h). Leachate solutions, previous centrifugation (3000 rpm) during 15 minutes, were filtered through PVDF syringe filters with tube tip (Whatmann, $25 \mathrm{~mm}$ diameter and $0.45 \mu \mathrm{m}$ pore size) and made up to $100 \mathrm{ml}$ volume in $1 \%(\mathrm{v} / \mathrm{v})$ $\mathrm{HNO}_{3}$. These solutions were analysed by ICP-OES, ICP-MS, and HR-ICP-MS. The analytical reproducibility was lower than 3\%. Given the physico-chemical characteristics of the samples studied, $\mathrm{Cl}$ and $\mathrm{S}$ concentrations were expressed as $\mathrm{Cl}^{-}$ and $\mathrm{SO}_{4}{ }^{2-}$, respectively. The methods to determine major and trace elements using ICPMS were described previously [16, 17]. Leaching concentrations have been expressed as $\mathrm{mg} \mathrm{kg}^{-1}$ (major elements) or $\mu \mathrm{gg}^{-1}$ (trace elements) of dry ash to compare directly the different experimental conditions tested. 


\subsection{Element selection}

Element selection covers the geochemical behaviour range of the main groups of elements implied and takes into account:

(1) the less mobile major elements during the leaching processes (i.e., Si, $\mathrm{Al}, \mathrm{Mn}$, $\mathrm{Fe}$, and $\mathrm{Ca}$ );

(2) highly soluble components $\left(\mathrm{SO}_{4}{ }^{2-}\right.$ and $\left.\mathrm{Cl}^{-}\right)$with preferential enrichment on tephra surfaces [18]; and

(3) elements dominantly combined with halogens and sulphate forming salts (e.g., $\mathrm{Na}, \mathrm{Mg}$ and $\mathrm{K}$ ) and acid droplets on particle surfaces in pristine ashes or associated with the volcanic glass dissolution during weathering for ancient ashes (e.g., $\mathrm{V}$ and Co) [19].

\subsection{Data processing and statistical analysis}

A Mixed Factorial Design (MFD) was employed as a multivariate strategy for the evaluation of the effects of selected control factors on the element stripping (Table 1). In our knowledge, it is the first time that this methodology is applied to the design of a leaching protocol for volcanic ashes. Thus, in addition to this section, details of statistical methods are provided in the Supplementary Material. Three variables (i.e., amount of sample (A), contact time (B), and L/S (C)) were regarded as factors, while the arithmetic mean of the element concentration $(n=4)$ for each batch leaching test was the dependent variable. The factor levels were selected according to previous works on ash leaching tests [15].

\section{Results and discussions}


A multivariate strategy was used to evaluate the experimental conditions affecting the leaching process, enabling graphical and numeric interpretations of the experimental, but avoiding complex and time-consuming one-at-a-time factor studies.

A MFD was built for the estimation of the effects of amount of sample (A), contact time (B), and $\mathrm{L} / \mathrm{S}(\mathrm{C})$ and its interactions (e.g. $\mathrm{AB}, \mathrm{AC}, \mathrm{BC}$ and $\mathrm{ABC}$ ). The first factor was evaluated at two levels, while the others at three levels (Table 1). Once outliers were removed from the data sets (one for 719 and one for CHA leaching tests, Tables 2a and $2 b)$, those factors that were not significant $(p>0.100)$ were removed to improve the models. The significance of each factor was then analysed by means of analysis of variance tests (ANOVA) and represented as Half-probability plots (Figures 1 and 2) at 95\% confidence level.

Figure 1 shows the results obtained for sample 719 which correspond to an ancient volcanic ash deposited some hundreds of thousands of years ago on land and subjected to hydrological and soil processes, which effectively removed any soluble salts attached to the surface of the ash particles. Thus, the chemical composition must have sourced from transformation processes during the weathering (i.e., hydrological and soil processes as oxidation and washing by meteoric water). Figure 2 shows the results obtained for sample CHA, a pristine ash with deposited salts on its surface that were formed in the plume of the volcanic eruption. This process occur through gasparticle interaction or the partial dissolution of the ash with acidic gases (i.e., mainly $\mathrm{SO}_{2}, \mathrm{HCl}$, and $\mathrm{HF}$ ) and aerosols (i.e., $\mathrm{H}_{2} \mathrm{SO}_{4}$ ), followed by precipitation at the ash-liquid interface, especially for elements with a low volatility in magma (lithophilic elements as $\mathrm{V}$ and Co) [18].

The outcome of these studies showed that in the case of the ancient sample, the amount of sample (factor A) had a significant effect over the releasing of alkali 
elements ( $\mathrm{Na}$ and $\mathrm{K}$ ). A reasonable explanation involves the solubilisation of their halide salts and by ionic exchange with $\mathrm{H}^{+}$as mechanism influencing the concentration of these elements in the leachates. Consequently, concentration in the liquid phase is limited only by the solubility and the $\mathrm{pH}$ solution. Beyond $\mathrm{Na}$ and $\mathrm{K}$ also $\mathrm{Al}$ and $\mathrm{Si}$ showed an influence of the amount of ash as well. In this case, they are solubilised by the destabilization of the silicate framework [13]. Both amount of ash (A) and leaching time (B) influenced the amount of $\mathrm{Mg}, \mathrm{Ca}, \mathrm{V}, \mathrm{Mn}, \mathrm{Fe}$, and Co implying exchange process with $\mathrm{H}^{+}$(once alkali elements were solubilised); but as their solubilised amount (and $\mathrm{pH}$ ) increases, they have the chance to precipitate or be adsorbed on the solid surface, generating changes in their concentration. With the exception of $\mathrm{SO}_{4}{ }^{2-}$ ion, none of the elements are influenced by the L/S ratio (C).

The scheme depicted with the pristine sample (Figure 2) was quite different in some cases. This fact is due to two main reasons: 1 ) the presence of salts and oxides in the ash surface are additional sources of metal; and 2) since neither natural weathering nor leaching have been occurred, there is still a number of non accessible sites in the solid structure, resulting in slower exchange kinetics. Phenomena of salt dissolution, ionic exchange (at first with $\mathrm{H}^{+}$, but later with alkali elements), precipitation and adsorption run consecutively. At this point, the mass (A) and leaching time (B) seems to be significant for all the elements studied. Exceptions to this are V (only the ash mass is significant) and Ca (only the contact time is significant).

In the light of the findings of the MFD, it is obvious that both mass and contact time are the control factors with the strongest influence on the leaching for the most elements; and the L/S ratio is influencing for fewer elements. Figures 3a, $3 b$ and $3 c$ depict 3D bar plots featuring the experimental domain, where the analyte responses (predicted) varies as a function of time and L/S when 0.1 or $1.0 \mathrm{~g}$ of ash was used. In 
those figures, the real values (white or black points) are compared with those adjusted (columns). It is evident that when the leaching tests were carried out with $1.0 \mathrm{~g}$ of ash, the analyte concentrations varied less with L/S or time as a general trend. This is to say that, within the levels selected, the higher the mass leached, the lower the effect of the other two control variables. The studentized residuals of the model also evidence this feature (see Supplementary Material). On the other hand, even at $1.0 \mathrm{~g}$ of ash, the effect of leaching time is more severe for $\mathrm{V}, \mathrm{Mn}, \mathrm{Fe}$ and Co than for alkaline earth elements, $\mathrm{Si}, \mathrm{Al}, \mathrm{Cl}$, and $\mathrm{SO}_{4}{ }^{2-}$. The role of mass as control factor is difficult to interpret from a chemical point of view. A possible explanation could be that differences in grain size distribution produced heterogeneities in samples of $0.1 \mathrm{~g}$. Larger sample mass should be investigated to shed further light to the results shown (e.g., 10, 50 and $100 \mathrm{~g}$ of ash).

The precision of the procedure is a combination of the errors of each individual step: sampling, weighing, sample preparation, dilution, sample application, development, detection, evaluation and calculation. As a consequence, precision must considered the degree of agreement among individual test results when the procedure is applied repeatedly to multiple samplings of a homogeneous sample. Box plots were performed (Figures 4a, b and c) to enable both graphical evaluation and comparison of the precisions at different experimental conditions for the two data sets. As it was expected from the all stated, the best conditions in terms of precision were achieved when $1.0 \mathrm{~g}$ of ash were leached in any set of conditions. Low amount of sample $(0.1 \mathrm{~g})$ is not always representative of the ash under study, because it is more difficult to reach the chemical equilibrium in these experimental conditions. In general, the leachant volume has a low influence on the element release when $1 \mathrm{~g}$ of sample is employed in the leaching tests. Lower reproducibility was obtained at high L/S ratio, mainly at high contact time. The working hypothesis to explain these findings is the incongruent 
dissolution of glasses and other compounds occurring in volcanic ashes, as in the early stages of weathering [8]. Furthermore, it is an interesting variable designing a leaching test due to analytical reasons. The choice of a high L/S ratio means a larger dilution, which could lead to the inconvenience of concentrations close or lower to the detection limits. In general, the lowest dispersion was observed when $1.0 \mathrm{~g}$ of ash was leached with L/S ratio equal to 10 and shaking during $4 \mathrm{~h}$.

\section{Conclusions}

The batch leaching principles of volcanic ashes have been examined in this work. Most of the soluble constituents of volcanic ash have been evaluated by one stage leaching tests. In this study we have shown that certain control factors significantly affect the results obtained in terms of concentration of elements relative to ash mass. Of the three factors studied, it was evident that the mass of ash affected not only the variability of the data, but also the influences of the other two factors (e.g., time of contact and liquid-to-solid ratio). The sample mass is difficult to explain as control factor from a chemical point of view and probably is consequence of sample heterogeneity associated with differences in grain size distribution among samples of $0.1 \mathrm{~g}$. Thus, the results are not conclusive on this feature and larger sample mass should be investigated to shed further light to the results shown.

With the available data, the recommended methodology for batch leaching tests of volcanic ashes is based on the use of a L/S ratio of 10, using $1.0 \mathrm{~g}$ of unsieved and unground ash and $10 \mathrm{ml}$ of ultrapure water, shaking the mixture for $4 \mathrm{~h}$. The entire method is completed within few hours, and its design is simple, feasible and reliable in laboratory conditions. 
The recommended protocol discussed in this work differs from protocols used in earlier studies and the protocol proposed by Witham et al. [15] (i.e., shake an ash-leach mixture for 90 min in a sealed container; using an ash (g) to water (ml) ratio of 1:25), which no longer seem appropriate to harmonize the obtained results. The main differences are related to the contact time (too short or too long than $4 \mathrm{~h}$ ). These findings demonstrate the need of define the optimum leaching conditions and adopt a standard protocol to leachate volcanic ash.

\section{Acknowledgements}

We acknowledge the technical support of ICTJA labGEOTOP Survey (M. Rejas), ICTJA DRX Survey (J. Elvira) and the Scientific-Technical Surveys of the University of Barcelona in the analytical work. This study was carried out in the framework of the

PEGEFA Working Group (Catalonian Government “Grup de Recerca Consolidat” 2009-SGR-972), and was partly funded by the Project ASH of the Spanish Ministry of Science and Technology (CGL2008-00099) and the FPU Grant of the Spanish Ministry of Education of one of the authors (F. Ruggieri, Ref. AP2006-04592). We gratefully acknowledge the comments of the anonymous reviewers and the journal editor that led to a much better manuscript. 


\section{References}

[1] S.J. Cronin, V.E. Neall, J.A. Lecointre, M.J. Hedley, P. Loganathan, Environmental hazards of fluoride in volcanic ash: a case study from Ruapehu volcano, New Zealand, J. Vol. Geotherm. Res., 121 (2003) 271-291.

[2] S.J. Cronin, D.S. Sharp, Environmental impacts on health from continuous volcanic activity at Yasur (Tanna) and Ambrym, Vanuatu, Int. J. Environ. Health Res., 12 (2002) 109-123.

[3] C. Stewart, D.M. Johnston, G.S. Leonard, C.J. Horwell, T. Thordarson, S.J. Cronin, Contamination of water supplies by volcanic ashfall: A literature review and simple impact modelling, J. Vol. Geotherm. Res., 158 (2006) 296-306.

[4] A. Lacroix, Les mineraux des fumerolles de l'eruption du Vesuve en avril 1906., Bull. Soc. Fr. Min., 28 (1907) 219-266.

[5] P. Allard, A. Aiuppa, H. Loyer, F. Carrot, A. Gaudry, G. Pinte, A. Michel, G. Dongarra, Acid gas and metal emission rates during long-lived basalt degassing at Stromboli volcano, Geophys. Res. Lett., 27 (2000) 1207-1210.

[6] M.T. Jones, S.R. Gislason, Rapid releases of metal salts and nutrients following the deposition of volcanic ash into aqueous environments, Geochim. Cosmochim. Acta, 72 (2008) 3661-3680.

[7] D.B. Smith, R.A. Zielinski, H.E. Taylor, M.B. Sawyer, Leaching characteristics of ash from the May 18, 1980, eruption of Mount St. Helens volcano, Washington, Bull. Vol., 46 (1983) 103-124.

[8] F. Ruggieri, J. Saavedra, J.L. Fernandez-Turiel, D. Gimeno, M. Garcia-Valles, Environmental geochemistry of ancient volcanic ashes, J. Hazard. Mater., 183 (2010) 353-365.

[9] M.A. Armienta, S. De la Cruz-Reyna, O. Morton, O. Cruz, N. Ceniceros, Chemical variations of tephra-fall deposit leachates for three eruptions from Popocatepetl volcano, J. Vol. Geotherm. Res., 113 (2002) 61-80.

[10] M. Edmonds, C. Oppenheimer, D.M. Pyle, R.A. Herd, Rainwater and ash leachate analysis as proxies for plume chemistry at Soufriere Hills Volcano, Montserrat, in: C.

Oppenheimer, D.M. Pyle, J. Barclay (Eds.) Flagship Meeting of the Geological-Societyof-London on Origins, Emissions and Impacts of Volcanic Gases, London, England, 2001, pp. 203-218.

[11] P. Frogner, S.R. Gislason, N. Oskarsson, Fertilizing potential of volcanic ash in ocean surface water, Geology, 29 (2001) 487-490.

[12] F. Risacher, H. Alonso, Geochemistry of ash leachates from the 1993 Lascar eruption, northern Chile. Implication for recycling of ancient evaporites, J. Vol.

Geotherm. Res., 109 (2001) 319-337.

[13] F. Ruggieri, J.L. Fernandez-Turiel, J. Saavedra, D. Gimeno, E. Polanco, J.A. Naranjo, Environmental geochemistry of recent volcanic ashes from the Southern Andes, Environ. Chem., 8 (2011) 236-247.

[14] P.S. Taylor, R.E. Stoiber, Soluble material on ash from active central-american volcanos, Geol. Soc. Am. Bull., 84 (1973) 1031-1041.

[15] C.S. Witham, C. Oppenheimer, C.J. Horwell, Volcanic ash-leachates: a review and recommendations for sampling methods, J. Vol. Geotherm. Res., 141 (2005) 299-326.

[16] J.L. Fernandez-Turiel, J.F. Llorens, F. Lopez-Vera, C. Gomez-Artola, I. Morell, D. Gimeno, Strategy for water analysis using ICP-MS, Fresenius J. Anal. Chem., 368 (2000b) 601-606.

[17] J.L. Fernandez-Turiel, A. Lopez-Soler, J.F. Llorens, X. Querol, P. Acenolaza, F. Durand, J.P. Lopez, M.E. Medina, J.N. Rossi, A.J. Toselli, J. Saavedra, Environmental 
monitoring using surface water, river sediments, and vegetation: a case study in the Famatina Range, La Rioja, NW Argentina Environ. Int., 21 (1995) 807-820.

[18] P. Delmelle, M. Lambert, Y. Dufrene, P. Gerin, N. Oskarsson, Gas/aerosol-ash interaction in volcanic plumes: New insights from surface analyses of fine ash particles, Earth. Planet. Sci. Lett., 259 (2007) 159-170.

[19] T.K. Hinkley, P.J. Lamothe, S.A. Wilson, D.L. Finnegan, T.M. Gerlach, Metal emissions from Kilauea, and a suggested revision of the estimated worldwide metal output by quiescent degassing of volcanoes, Earth. Planet. Sci. Lett., 170 (1999) 315325. 


\section{Figure Captions}

Figure 1. Half-Normal probability plot of the normalized effects of the selected factors: A, amount of ash; B, contact time; C, L/S ratio for sample 719 (p-values obtained by ANOVA not included). Only model terms are labeled.

Figure 2. Half-Normal probability plot of the normalized effects of the selected factors: A, amount of ash; B, contact time; C, L/S ratio for sample CHA (p-values obtained by ANOVA not included). Only model terms are labeled.

Figure 3. Model predictions as a function of contact time and L/S. a) alkali and alkaline earth elements; b) transition metals and c) $\mathrm{Al}, \mathrm{Si}, \mathrm{Cl}$ and $\mathrm{SO}_{4}{ }^{2-}$.

Figure 4. Box plots $(n=4)$ of the experimental results obtained for each element. a) alkali and alkaline earth elements; b) transition metals and c) $\mathrm{Al}, \mathrm{Si}, \mathrm{Cl}$ and $\mathrm{SO}_{4}{ }^{2-}$. Leachant volume is expressed in $\mathrm{ml}$. 


\section{Supplementary Material}

There are two files in Supplementary Material

1- Statistical methods

2- Figure 1 of Supplenatry Material

\section{Figure Caption of Supplemntary Material}

Figure 1 of Supplementary Material. Studentized residuals of the model versus experiment number: a) $0.1 \mathrm{~g}$ of ash; b) $1.0 \mathrm{~g}$ of ash. 


\section{Supplementary material}

\section{Statistical methods}

A Mixed Factorial Design (MFD) was used considering three variables (i.e., amount of sample (A), contact time (B), and L/S (C)) as factors, while the arithmetic mean of the element concentration $(n=4)$ for each batch leaching test was the dependent variable. The factor levels were selected according to previous works on ash leaching tests [15]. The MFD was built with the factor A at two levels and the factors B and C at three levels resulting in $2^{1 *} 3^{2}=18$ experiments (Tables $2 \mathrm{a}$ and $2 \mathrm{~b}$ ). After the effects were estimated, their significance $(\mathrm{p}<0.05)$ was evaluated by means of ANOVA tests and Half-Probability plots (Figures 1 and 2) using STAT-EASE Design Expert v 8.0.1 (trial version). The adjusted polynomial models along with the residuals are also represented in Figures 3 and 4. The data sets for the selected elements were further represented in box-plots (STATA 10.0). Box represents the $25^{\text {th }}$ and $75^{\text {th }}$ percentiles and the solid line within the box is the median of the four replicates used for each experiment. Analysis of variance (ANOVA), using the analyte concentration as response factor, was used to estimate the significance of the effects. The regression models from the ANOVA tests are useful to determine both the anticipated leachate concentrations as well as estimates of the uncertainties associated with those predictions. The experimental data were adjusted to a polynomial model:

$$
\mathrm{Y}=\mathrm{x}_{0}+\mathrm{x}_{1} \mathrm{~A}+\mathrm{x}_{2} \mathrm{~B}+\mathrm{x}_{3} \mathrm{C}+\mathrm{x}_{4} \mathrm{AB}+\mathrm{x}_{5} \mathrm{AC}+\mathrm{x}_{6} \mathrm{BC}
$$

Where $\mathrm{Y}$ is the dependent variable (analyte concentration); $\mathrm{A}, \mathrm{B}$ and $\mathrm{C}$ are the main effects terms of factors $\mathrm{A}, \mathrm{B}$ and $\mathrm{C}$ respectively; $\mathrm{AB}, \mathrm{AC}$ and $\mathrm{BC}$ are the two-factor interaction terms; and $\mathrm{x}_{1}$ to $\mathrm{x}_{6}$ are the model (adjusted) coefficients. 
In terms of predictability and potential sources of lack of fit, the effect of the sample amount is shown in plots of the studentized residuals versus the experiment number (Figures 1a and 1b of Supplementary Material).

Figure 1 of Supplementary material. Studentized residuals: a) $0.1 \mathrm{~g}$ of ash; b) $1.0 \mathrm{~g}$ of ash. 


\section{A: mass $=1.0 \mathrm{~g}$}
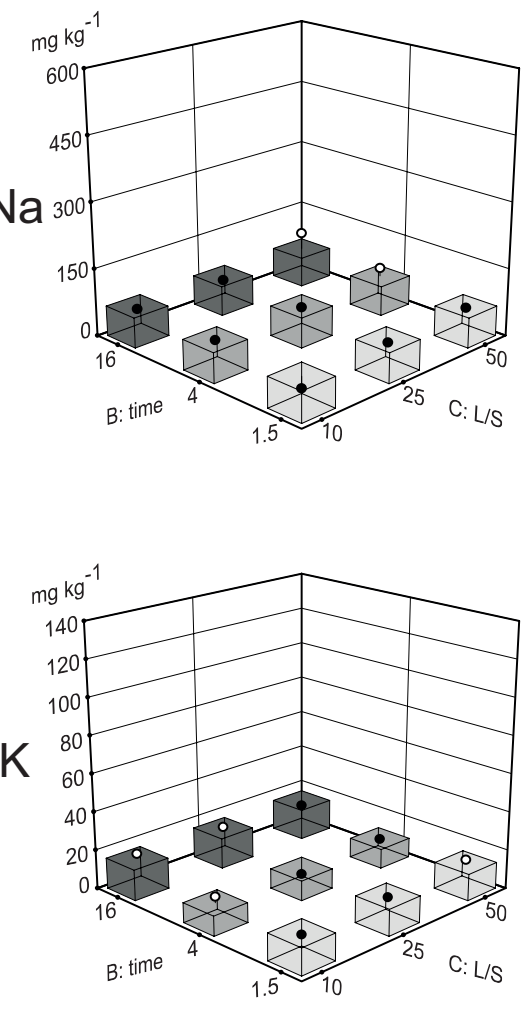

$\mathrm{Mg}$

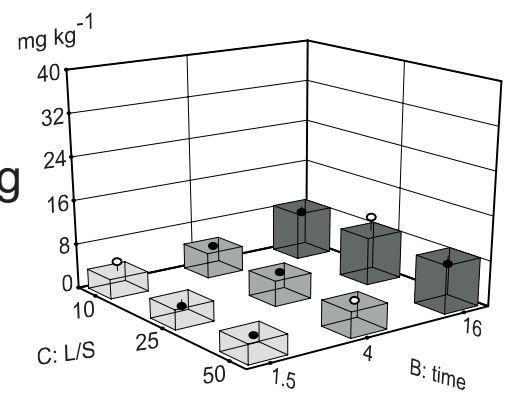

A: mass $=0.1 \mathrm{~g}$
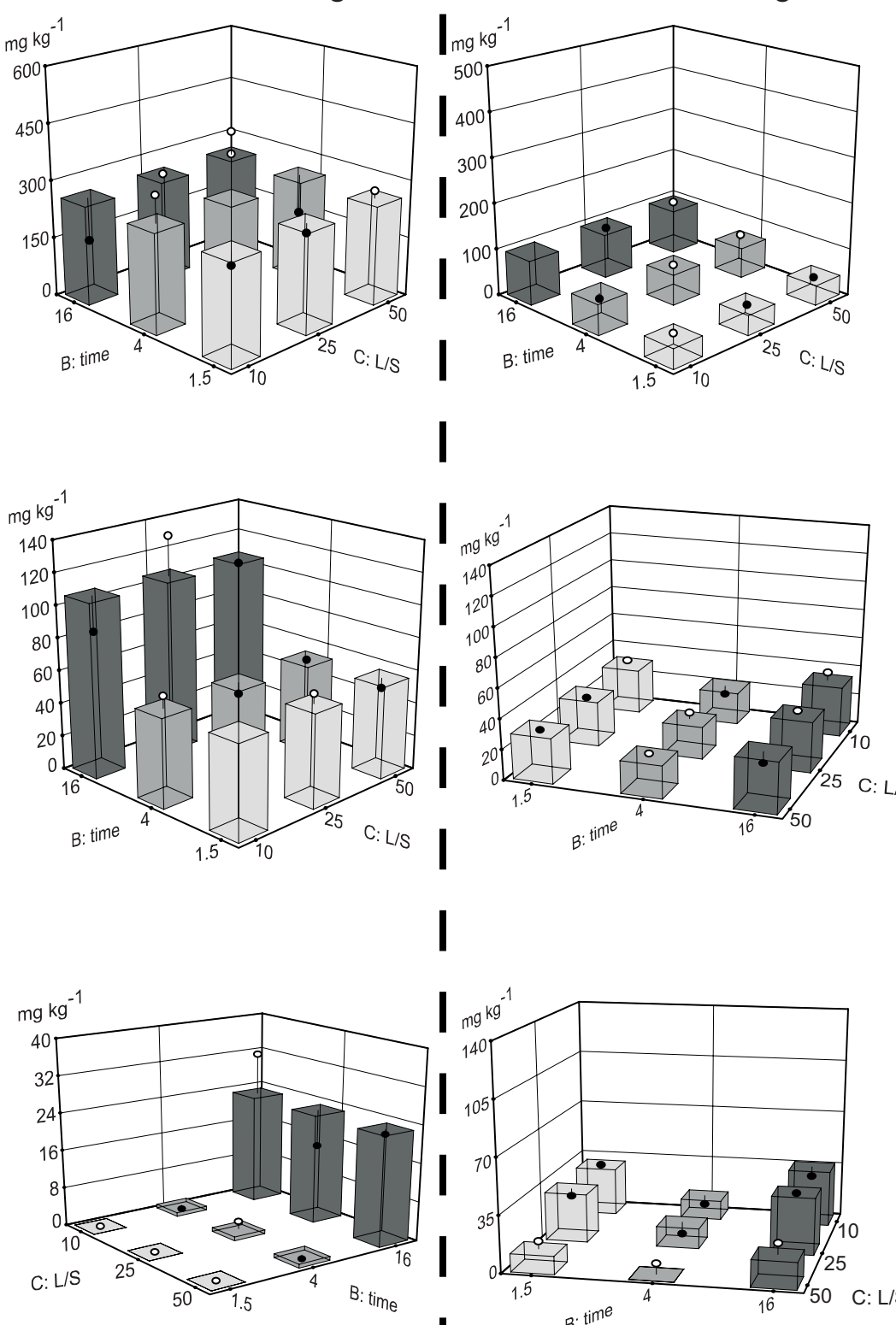

I $\quad$ : mass $=1.0 \mathrm{~g}$

$\mathrm{mg} \mathrm{kg}^{-1}$

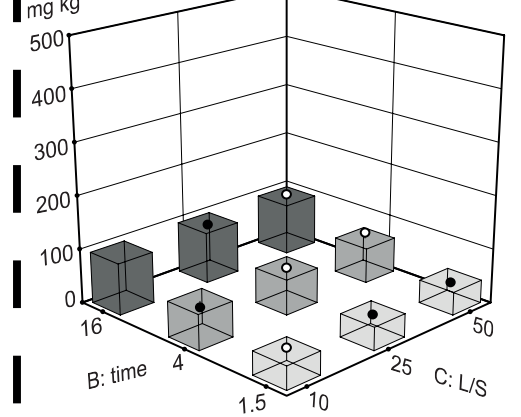

I

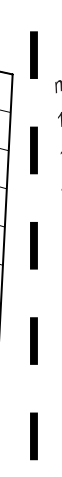

I
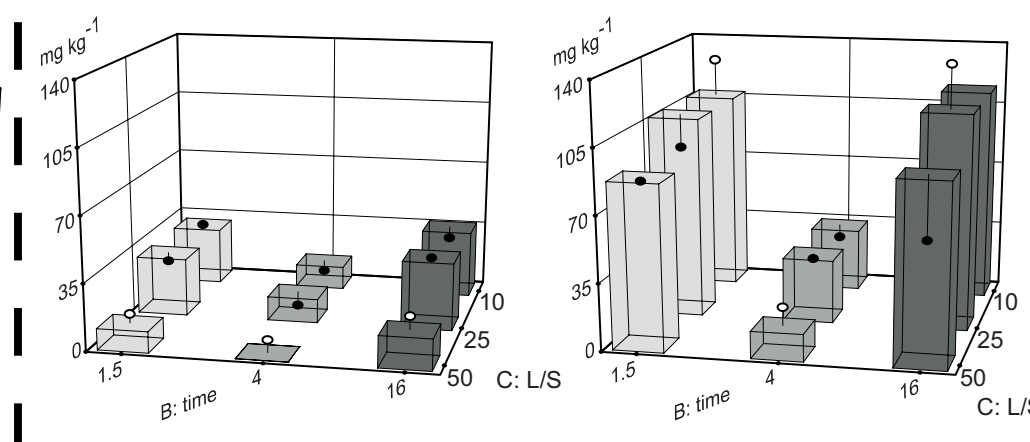

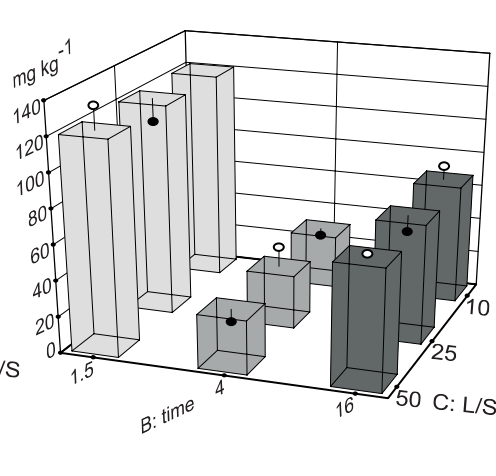

A: mass $=0.1 \mathrm{~g}$

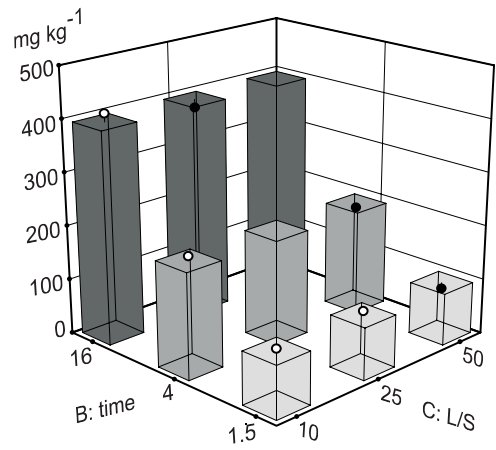

C: L/S
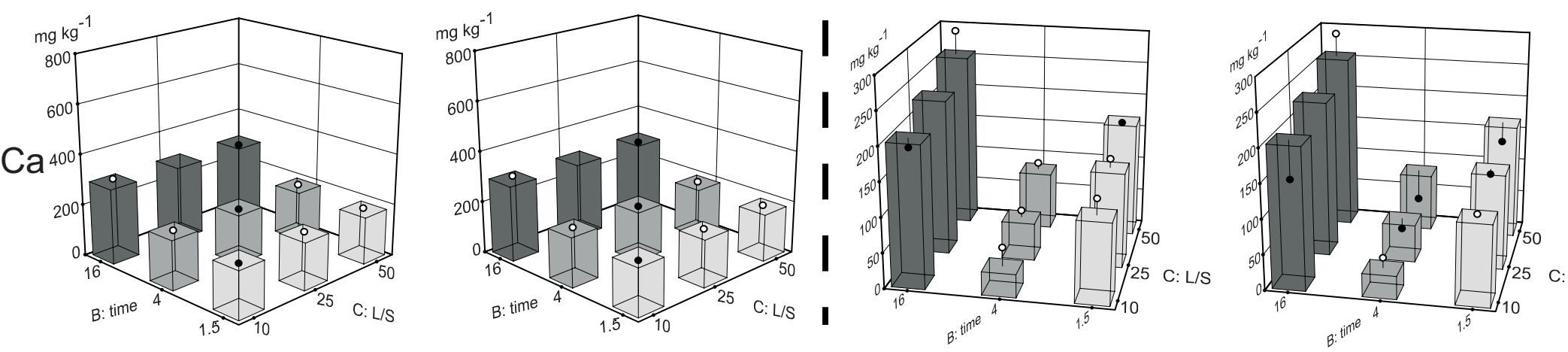

SAMPLE-719 
$\mathrm{A}:$ mass $=1.0 \mathrm{~g}$
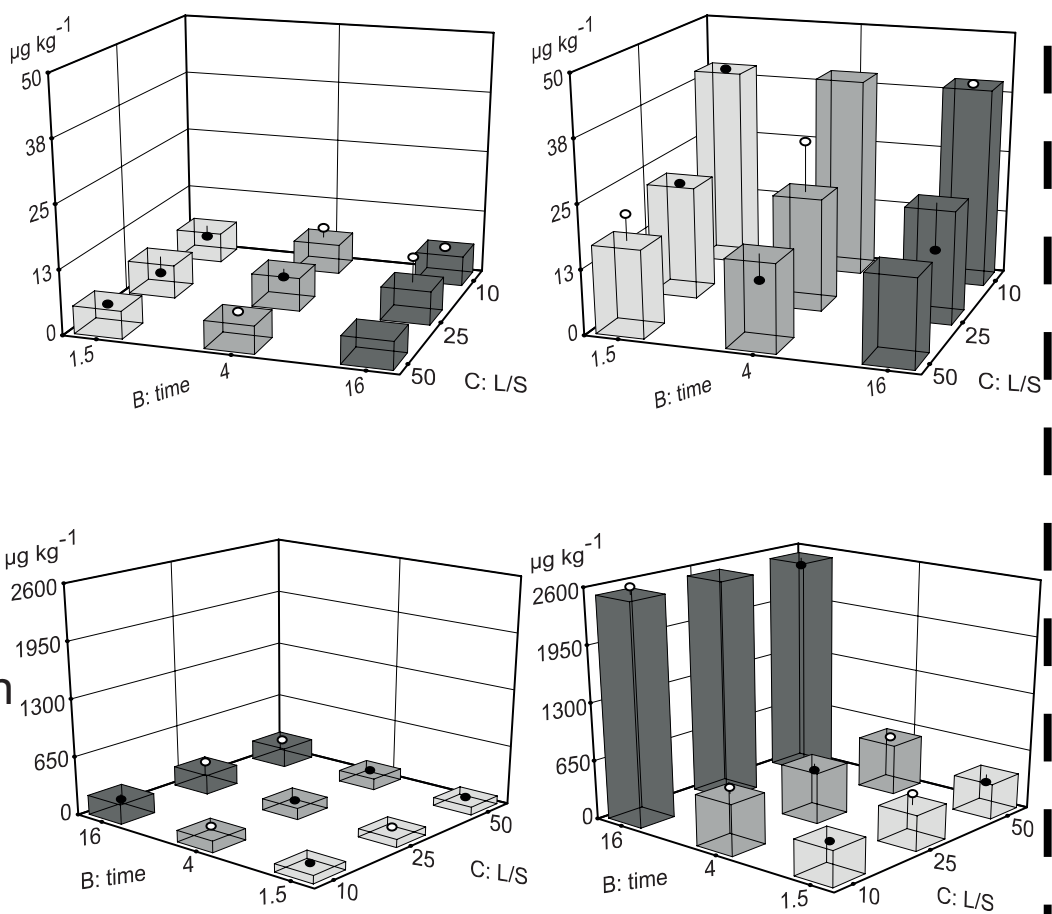

I

A: mass $=0.1 \mathrm{~g}$

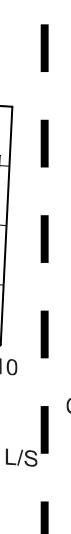

A: mass $=1.0 \mathrm{~g}$
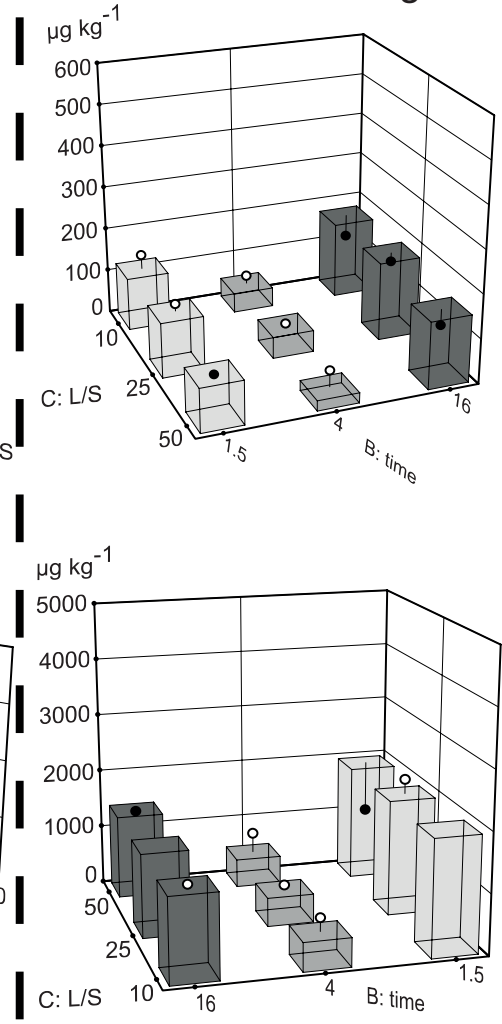

I

$\mu \mathrm{g} \mathrm{kg}$
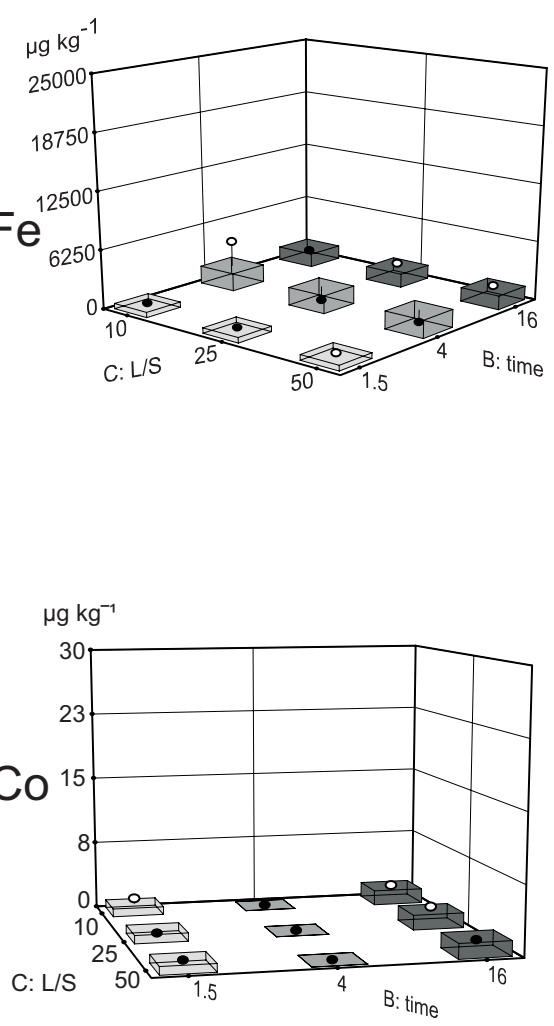

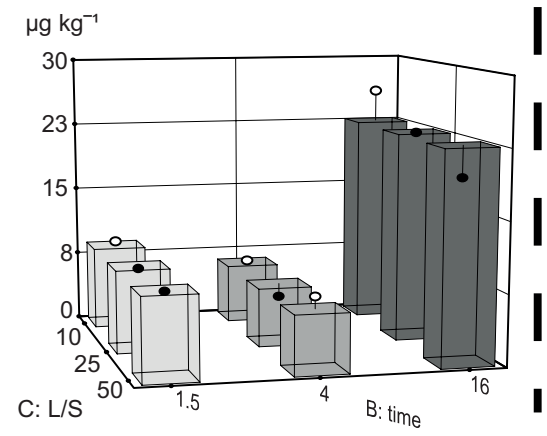

C: L/S

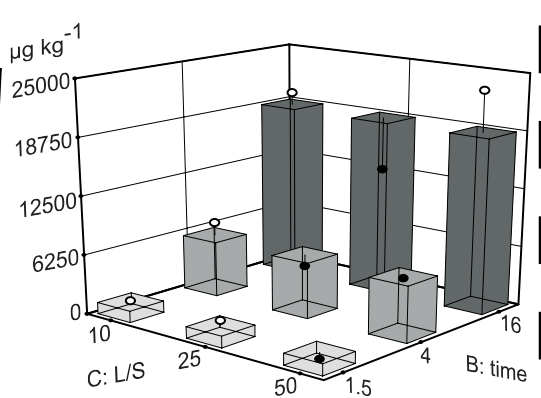

I

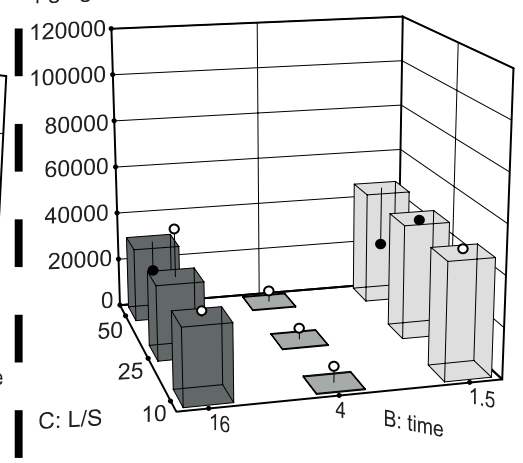

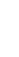

$\mu \mathrm{gg}^{-1}$

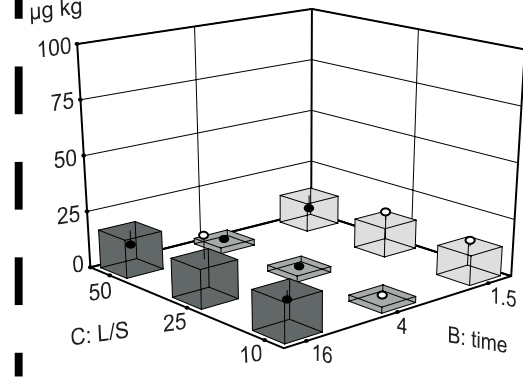

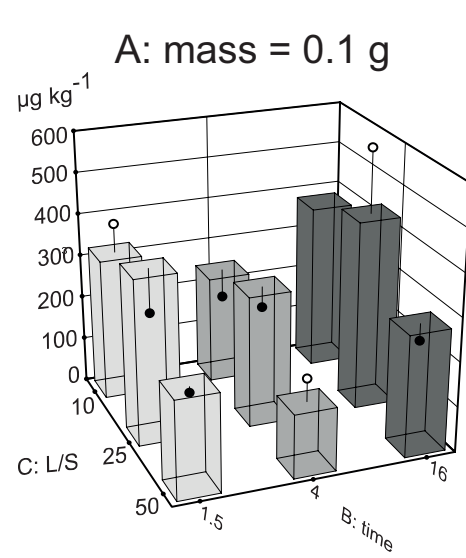
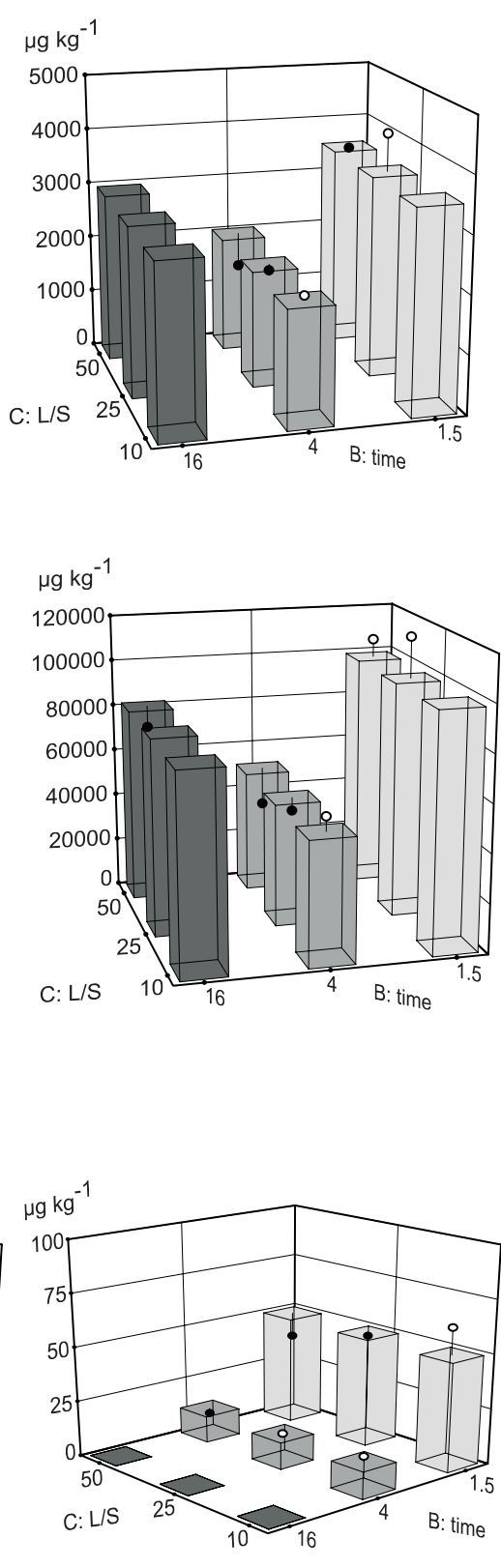

$\mathrm{A}:$ mass $=1.0 \mathrm{~g}$
$A:$ mass $=0.1 \mathrm{~g}$
$\mathrm{A}:$ mass $=1.0 \mathrm{~g}$

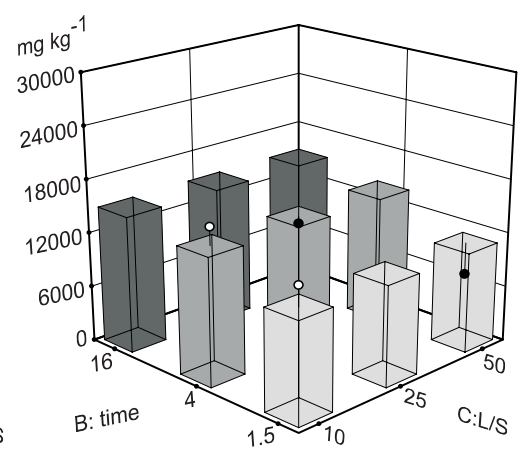

B: time

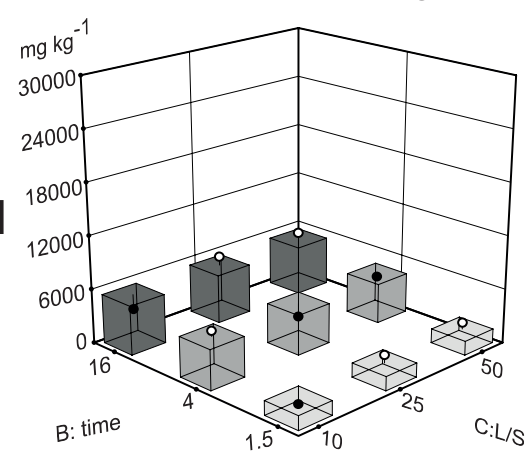

Si
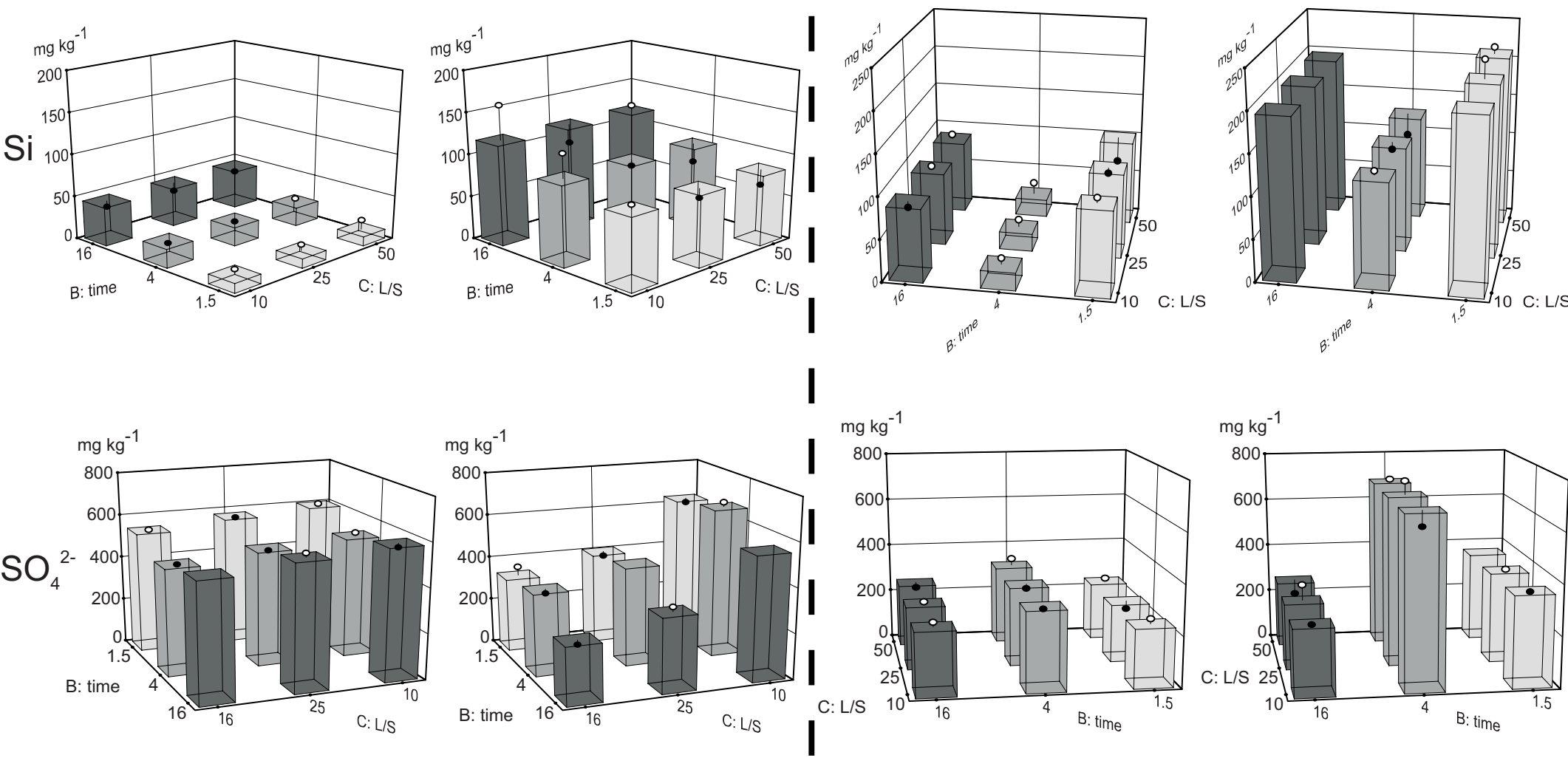

$\mathrm{mg} \mathrm{kg}^{-1}$

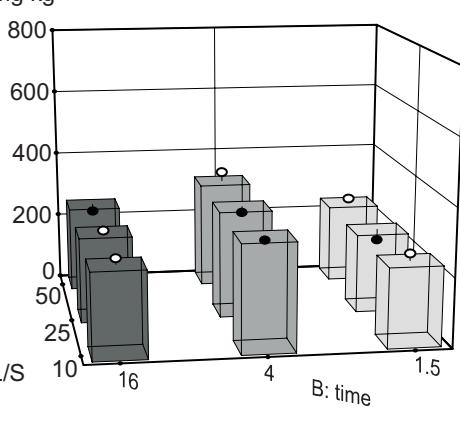

$\mathrm{mg} \mathrm{kg}^{-1}$

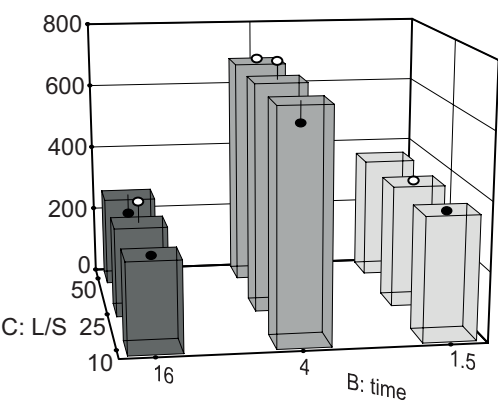

C
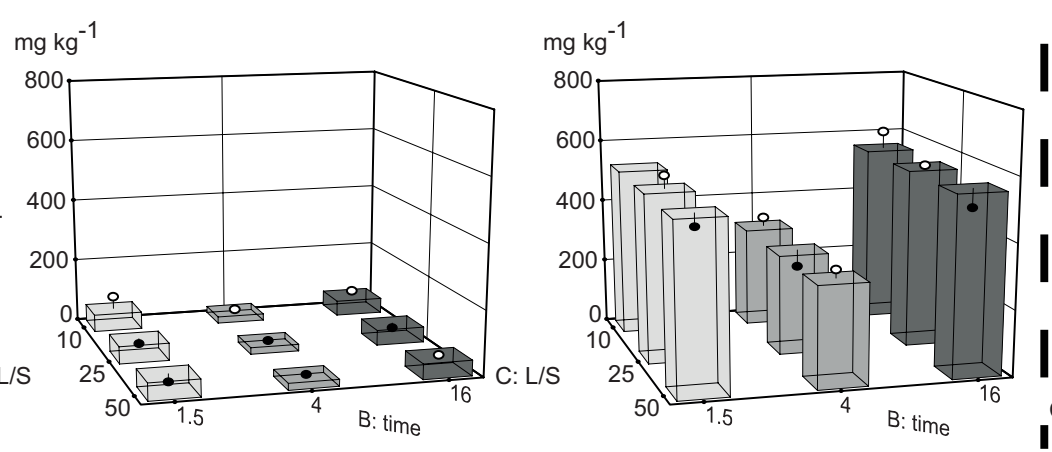

$\mathrm{A}:$ mass $=0.1 \mathrm{~g}$

$\mathrm{mg} \mathrm{kg}{ }^{-1}$

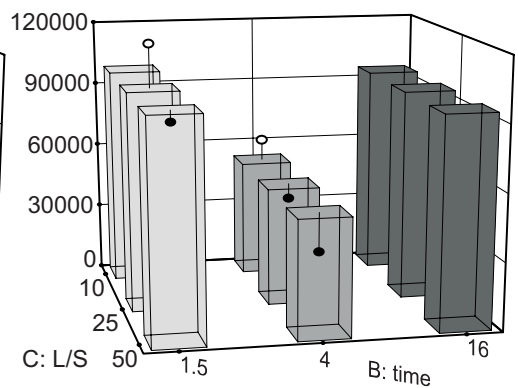

$\mathrm{mg} \mathrm{kg}^{-1} \quad \mathrm{mg} \mathrm{kg}^{-1}$

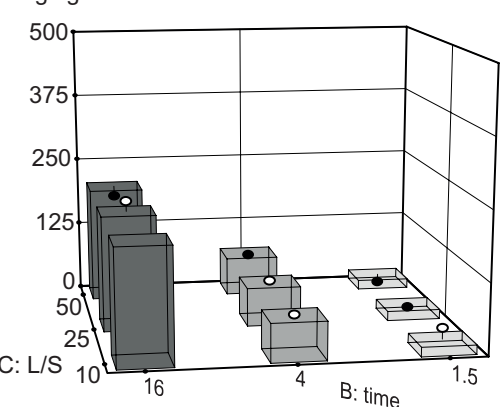

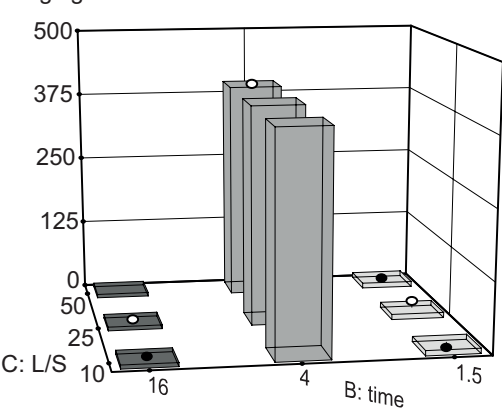

SAMPLE-CHA

- Design points below predicted value

$\bigcirc$ Design points above predicted value 
SAMPLE-719
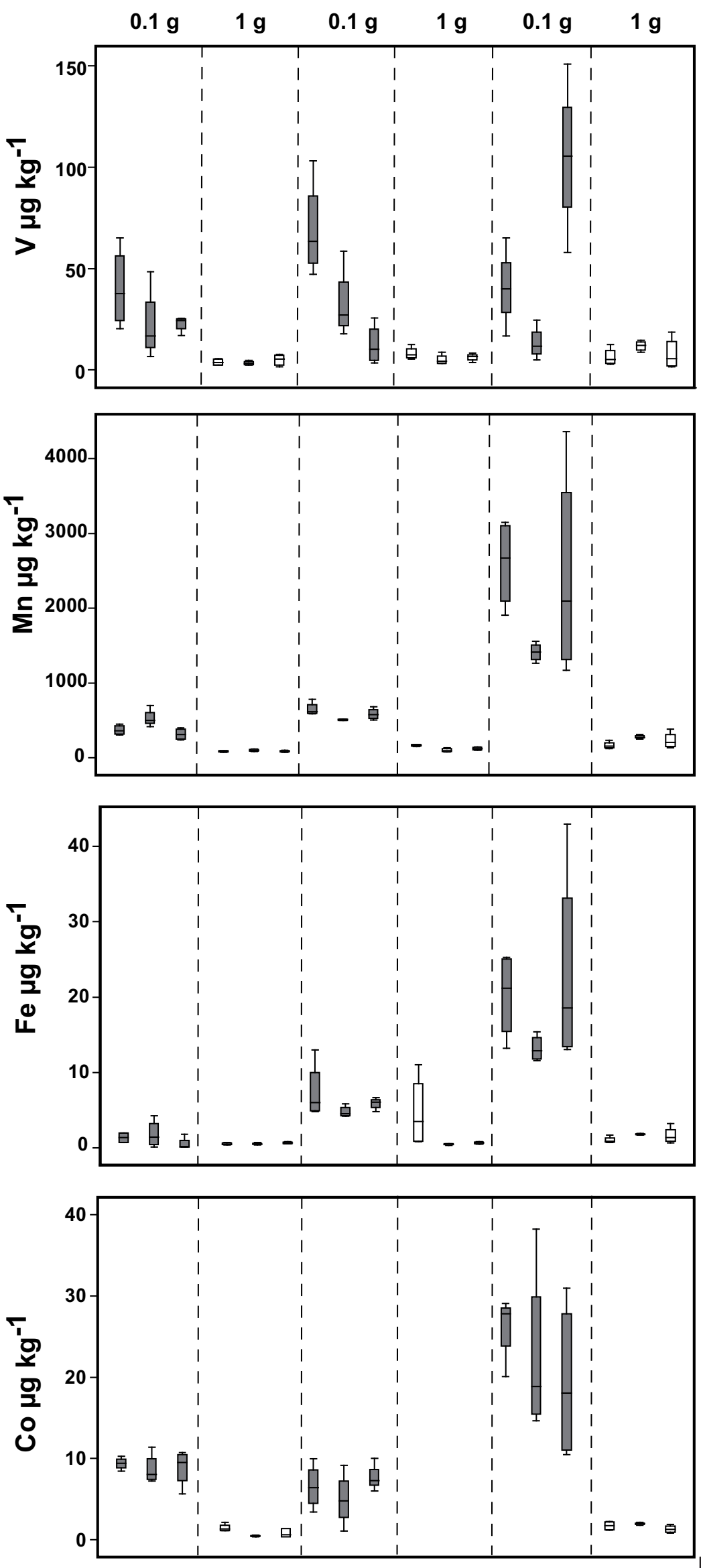

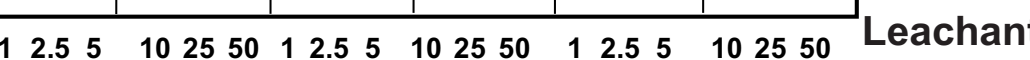
volume
SAMPLE-CHA
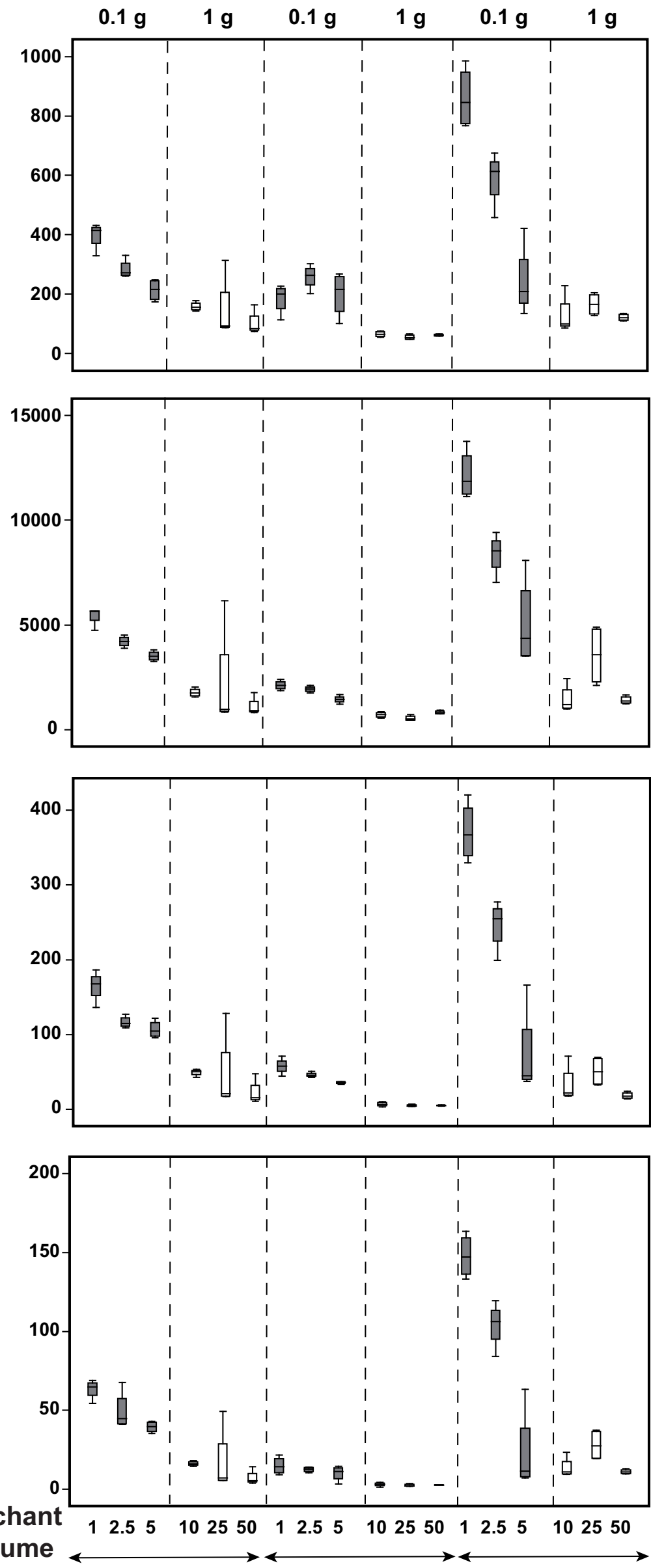
SAMPLE-719
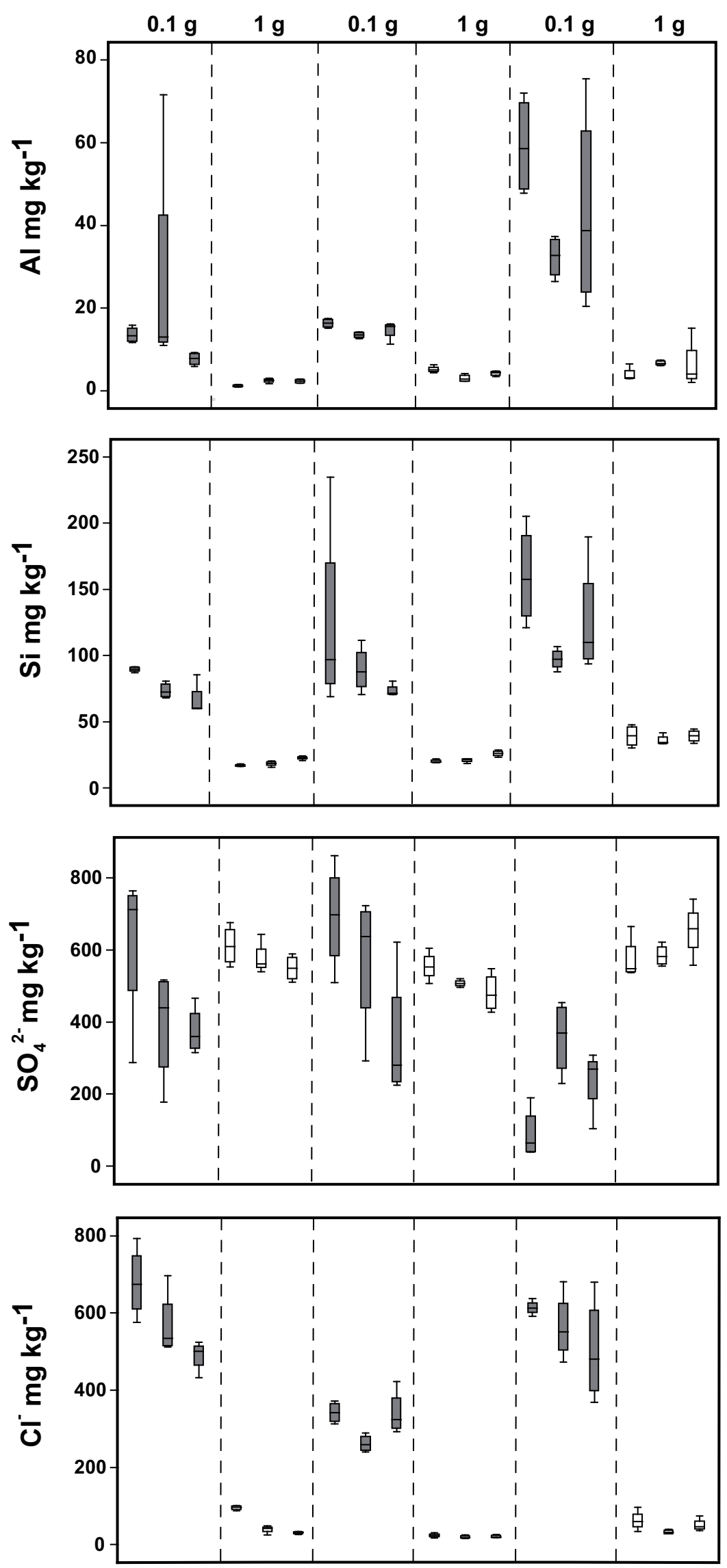

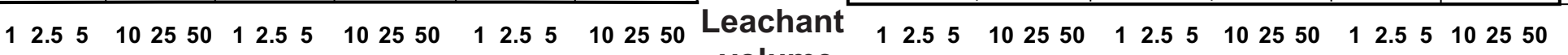

SAMPLE-CHA
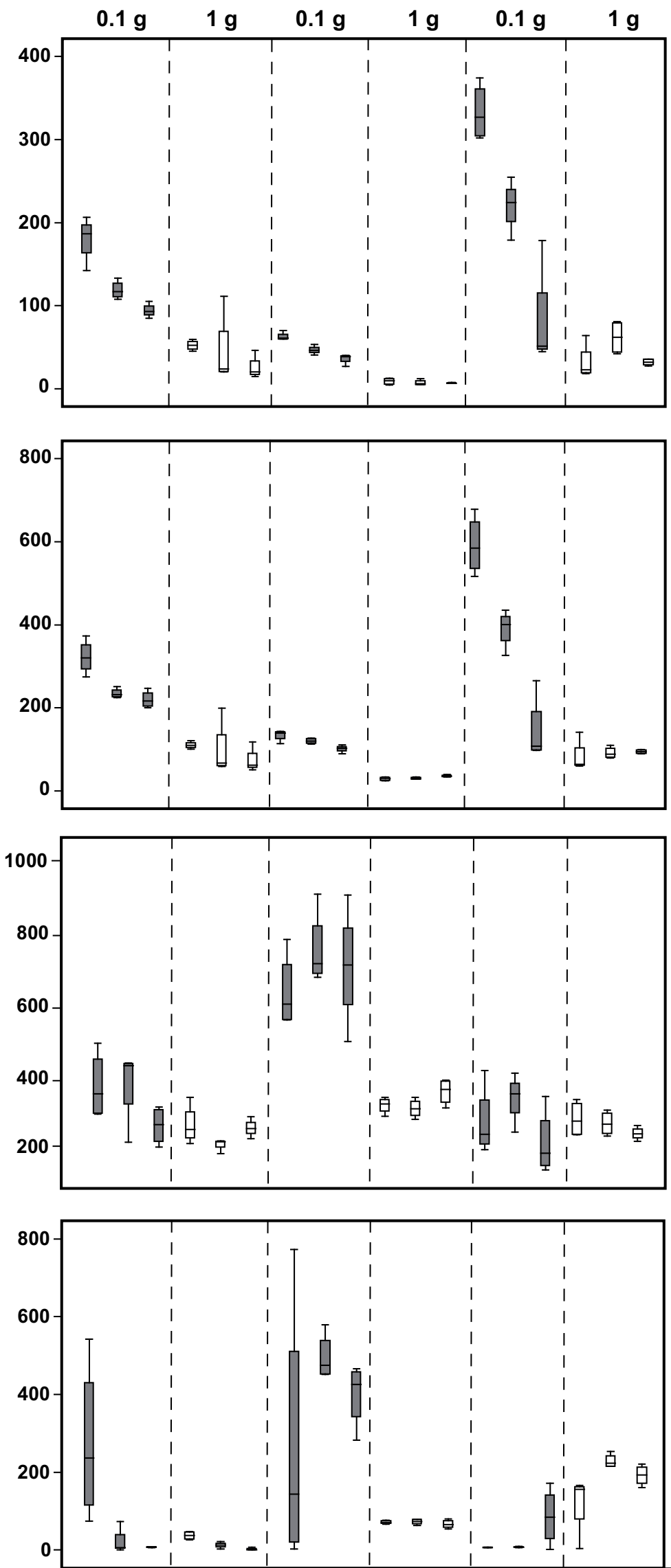
volume$$
\text { « }
$$ 
